\title{
Inspection based risk management of electric distribution overhead lines
}

\author{
Adnan Hasan Tawafan', Dhafer Mayoof Alshadood ${ }^{2}$, Fatima Kadhem Abd ${ }^{1}$ \\ ${ }^{1}$ Al-Furat Al-Awsat Technical University, Technical Institute Karbala, Karbala, Iraq \\ ${ }^{2}$ Southern Technical University, Nasiriyah Technical Institute, An-Nashiriyah, Iraq
}

\begin{tabular}{l} 
Article Info \\
\hline Article history: \\
Received Jul 27, 2021 \\
Revised Dec 24, 2021 \\
Accepted Jan 4, 2022 \\
\hline Keywords: \\
Distribution network \\
Reliability indices \\
Risk management \\
Shortest path problem
\end{tabular}

\begin{abstract}
This paper introduces a comprehensive process based on inspection for determination of medium voltage (MV) overhead line condition and it was tried that all factors influencing the outage of distribution network integrated into one index that called condition index. A condition based failure rate model has been proposed and its unknown parameters are calculated based on historical data. Shortest path problem (SPP) model has been proposed for the long term scheduling of maintenance and reinvestment. Objective function includes sum of the reinvestment, maintenance costs, failure costs and energy not supplied (ENS) costs with considering budget and labor constraints. Finally, as a result of this research, optimal combination of various actions such as reinvestment, preventive maintenance (PM) and tree trimming and it's scheduling has been determined over the ten and five-year horizon. Results confirmed acceptable performance of proposed method because of compliance with actual condition and engineering judgment.
\end{abstract}

This is an open access article under the $\underline{C C B Y-S A}$ license.

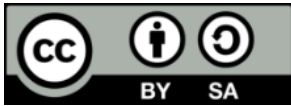

\section{Corresponding Author:}

Adnan Hasan Tawafan

Al-Furat Al-Awsat Technical University, Technical Institute Karbala

Iraq

Email: towfana@yahoo.com

\section{INTRODUCTION}

Overhead lines are important components in the distribution of electrical energy. According to statistics, a large percentage of electricity costs, and most costumers' outage, occur in the distribution network. In fact, about $80 \%$ of the customers' outage are due to a failure in the distribution network [1]. Distribution networks in urban and rural areas often consist of overhead feeders. Poles, cross arms, insulators, jumpers, conductors and transformers are overhead distribution network equipment, thus forming a complex and repairable system. Conditions of all these component should be monitored, because the condition of each component will influence the overall condition of an overhead line [2]. Distribution companies strive to reduce their operation costs for achieving greater profits and maintaining their competitiveness [3]. In this regard, it is of great importance to reduce maintenance and repair costs, which constitute a significant part of the costs of operating the distribution network. Outages can be divided into four major categories. First, the failures that result from aging and failure of equipment and are related to the health of equipment and their service life. The second category is caused by wrong design and external factors and not related to the life and health of the equipment. The third category is due to the impact of trees and because the conductors are bare and also lack of timely trimming of the trees. Finally, the fourth category is caused by other factors such as human error and unknown factors. This information indicates that maintenance can only prevent one-third of the outages. According to experts, more than half of the unknown outage are most likely due to external factors. Therefore, to prevent the occurrence of nearly half of outages, 
the design of the network must be changed and retrofitted against external factors. Therefore, failure rate modeling based on the age of the equipment does not seem to be realistic and is therefore a perfect model that takes into account the effects of environmental and external factors. As well as reflect the effect of performing corrective/preventive maintenance and reinvestment actions in failure rate improvement.

Various methods have been used for evaluating and optimizing the risk, reliability and maintenance scheduling in distribution networks. As demonstrated in [4] utilized dynamic scheduling for long term maintenance management [5], [6], decision tree [7], [8], cost-benefit ratio [9]-[11], markov method [12], monte carlo [13]-[15]. Are the methods that risk and reliability of a network have been evaluated by them. The shortest path problem (SPP) method has been used in this study. SSP has been used for solving many different problems in the power system [16], [17]. Five actions are proposedfor managing risk in distribution networks, one option is to make no action during the network scheduling period, the next action is reinvestment for changing the design of the network and three actions are proposed for reinvestment.

\section{RISK MANAGEMENT ACTIONS}

The purpose of this study is to investigate the implementation of risk management in real distribution network. Risk management means reducing or keeping the risk at the optimal level using available and possible tools. But what tools do we have for risk management? Maintenance is only one of the risk management action, other tools such as replacement and reinvestment are available, and the choice of each of these action in each interval depending on the goals and constraints of each action. In describing the objectives, the expected level of risk can be mentioned. This issue that how much we want to reduce the risk depends on the goals and the prospects. Among the limitations are budget constraints and human resources that are influencive in achieving goals because we may not achieve the desired level of risk given these constraints.

Our available and proposed actions for managing risk in distribution networks are illustrated in Figure 1. These actions include five categories. One option is to make no action during the network scheduling period. As a result, no budget are incurred, but the network situation worsens and the failure rate increases, imposing additional costs on the distribution companies, including the cost of the failures and energy not supplied. Another action is network maintenance. This means that we reduce the risk of network outages without drastically changing the network design by taking preventive and corrective actions. Maintenance can include tree trimming, minor maintenance and major maintenance. Therefore, the cost and effectiveness of each level of maintenance vary. The next action is reinvestment for changing the design of the network. Sometimes no level of maintenance can fix some of the outage, so it is essential that the design of the network be changed. For this purpose, based on the experiences of different countries and references, three actions are proposed for reinvestment as shown in the Figure 1.

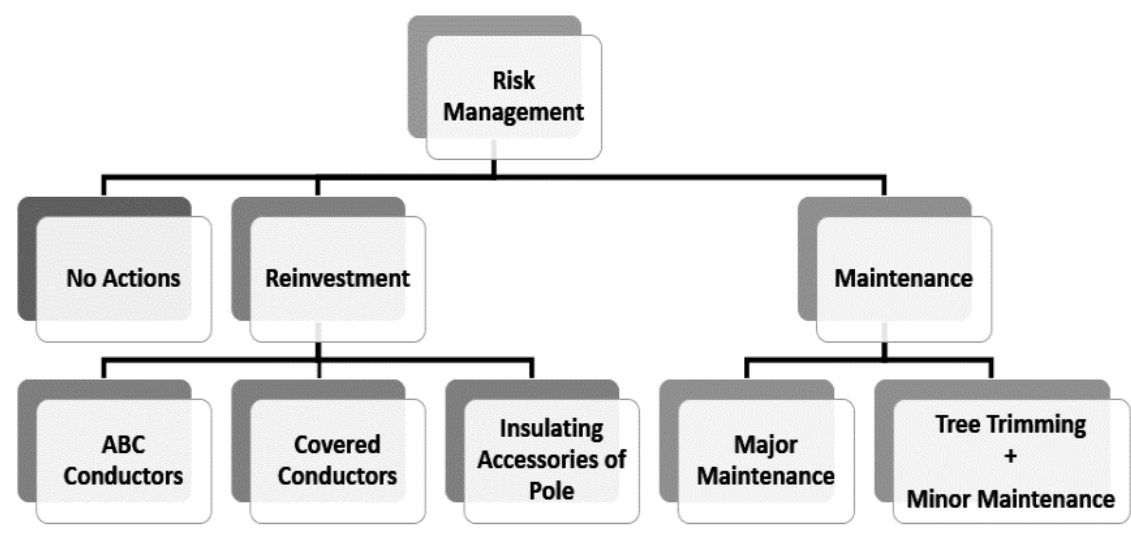

Figure 1. Risk management actions

\section{RISK MANAGEMENT MODEL}

The proposed risk management model is that we are faced with a choice of several actions in each period (e.g. a year). These actions include several maintenance actions and several investment actions that are selected according to the constraints and goals of the asset managers. The SPP is to find the optimum path from node 1 to end node $\mathrm{n}$, which can be formulated as shown in the form of integer programming [18]: 


$$
\begin{aligned}
& \min Z=\sum_{i=1}^{n} \sum_{i=1}^{n} c_{i, j} x_{i, j} \\
& \text { s.t } \sum_{j=1}^{n} x_{i, j}-\sum_{k=1}^{n} x_{k, i}= \begin{cases}1 & (i=1) \\
0(i=2,3, \ldots, & n-1) \\
-1 & (i=n)\end{cases} \\
& x_{i, j}=0 \text { or } 1 \quad \forall i, j
\end{aligned}
$$

where $\mathrm{Z}$ is zone number. In the (2) and (3), we have: indices $i, j, k$ : index of node $(1,2, \ldots, \mathrm{n})$; parameters $\mathrm{n}$ : number of nodes and $c_{i, j}$ : transmission cost of arc $(i, j)$; decision variables (binary) $x_{i, j}$ : the link on an arc $(i, j)$.

\subsection{Risk formulation}

The factors that are defined under the risk index include the risk of human injury and breaking safety and/or environment laws and the risk arising from a customer power outage [19]. There are also other common categories in the electricity distribution system such as financial risk, safety risk, environmental risk, supply quality risk, reputation risk, vulnerability risk and law risk [20]. Some references also categorize risk factors as limited to financial, safety, network performance and environmental risk [21].

In analyzing and evaluating different risk reduction actions it should be considered, that performing on not performing of each action what effect does it have on the risk factors. In this paper, only financial risks are considered. One of the economic indices of analysis for long-term scheduling is net present value (NPV) that considering discount rate, transfers all annual costs to the present year. Since the objective function is financial, therefore the analysis can be made through net present value function as shown in (4):

$$
C_{N P V}=\sum_{t=1}^{n} C \times(1+D R)^{-n}
$$

where DR is discount rate, the economic or financial risk itself includes reinvestment, renovation costs, operation, maintenance, repairs, damage costs, costumer outage cost such as energy not supplied (ENS) costs and revenue loss cost. Note, because many scheduled maintenance programs perform in a hot line, we neglect the costs of the planned outage.

$$
\begin{aligned}
\text { Minimize } C F= & \sum_{z=1}^{N Z} \sum_{t=1}^{T} \sum_{k=1}^{N D}\left(\left(I N V_{z}^{k}(t) \times \gamma_{z}^{k}(t)\right)+\left(C_{z}^{k, M T}(t) \times X_{z}^{k}(t)\right)\right. \\
& \left.+\left(C_{z}^{F}(t) \times \lambda_{z}(t)\right)\right) \times\left(1+D R^{-1}\right)
\end{aligned}
$$

Where $\gamma_{z}^{k}(t)$ is binary variable related to investment actions, $X_{z}^{k}(t)$ is binary variable related to maintenance actions, $C_{z}^{k, M T}(t)$ is total cost related to the kth maintenance action of zone $\mathrm{z}$ in interval $\mathrm{t}$ and $C_{z}^{F}(t)$ is total cost related to the outage occurred on zone $\mathrm{z}$ in interval $\mathrm{t}$.

\subsubsection{Reinvestment cost}

Three actions are proposed for reinvestment $\mathrm{ABC}$ conductor, cover conductor and covering accessories of pole. To calculate reinvestment costs, we need to know the amount of capital needed to run each action per kilometer. Therefore, the equation of investing in the distribution network are as shown in (6).

$$
I N V_{z}^{k}=i n v^{k} \times L_{z}
$$

where $\mathrm{k}=1$ : covering accessories of pole; 2 : cover conductor; 3 : ABC conductor.

\subsubsection{Energy not served (ENS) cost}

ENS means the amount of energy demand measured in MWh which is not supplied in a given zone and in a given time period due to insufficient resources to meet demand. ENS costs include budget and labor constraints. It can calculate as shown in (7) and (8). 


$$
\begin{aligned}
& E N S_{Z}^{U P}=P_{z} \times D_{z}^{U P} \\
& C_{E N S, Z}^{U P}=C_{k W h} \times E N S_{Z}^{U P}
\end{aligned}
$$

\subsubsection{Revenue loss cost}

The economic or financial risk itself includes revenue loss cost. Total revenue loss cost is calculated by multiplying the ENS cost per unit by the quantity sold. It can calculate as shown in (9).

$$
C_{R e v, Z}^{U P}=C_{E} \times E N S_{Z}^{U P}
$$

\subsubsection{Maintenance cost}

The term maintenance cost refers to any cost incurred by an individual or business to keep their assets in good working condition. These costs may be spent for the general maintenance of items like price of one working hour necessary for the kth maintenance action or they may be used for repairs. It is calculate as shown in (10):

$$
C_{z}^{k, M T}(t)=\left(\left(\left(C_{\text {Labor }}^{k, M T} \times \text { Labor }^{k, M T}\right)+C^{k, M c o m p}\right) \times L_{z}\right)
$$

where $\mathrm{k}$ is 1 for minor maintenance, 2 for major maintenance or 3 for tree trimming.

$$
C^{k, M \operatorname{comp} p}=\sum_{j=1}^{N M_{k}} C_{j}^{k, \text { comp }}
$$

As demonstrated in (10) means that each maintenance action includes more minor items. As an example for minor maintenance, the cost of non-standard span correction, replacement of fittings and correction of defective tie conductor is calculated separately or for major maintenance, replacement cost of failed insulators and poles, and cost of failed equipment are calculated separately.

\subsubsection{Failure costs}

Failure costs include price of one working hour necessary for repairing fault occurred, number of working hours necessary for repairing the fault, unplanned ENS Cost per megawatt-hour for zone $\mathrm{z}$ and revenue lost due to unplanned ENS resulted from outage occurred on zone z. It is calculate as shown in (12).

$$
C_{Z}^{F}(t)=\left(\left(C_{\text {Labor }}^{R} \times \text { Labor }^{R}\right)+C^{R c o m p}\right)+\left(C_{E N S, z}^{U P}+C_{R e v, z}^{U P}\right) \times(1+q)^{t-1}
$$

\subsubsection{Constraints}

Constraints refer to total cost related to the kth maintenance action of zone $\mathrm{z}$ in interval $\mathrm{t}$, total cost related to the outage occurred on zone $\mathrm{z}$ in interval $\mathrm{t}$, capital Investment associated with the kth investment action of zone $\mathrm{z}$ in interval $\mathrm{t}$, number of working hours necessary for the kth maintenance action, number of working hours available in interval $t$ for tree trimming and number of working hours available in interval $t$ for minor and major maintenance or repair. All constraints can calcutale as shown in (13)-(17).

$$
\begin{aligned}
& \sum_{z=1}^{N Z} \sum_{k=1}^{N D}\left(\left(C_{z}^{k, M T}(t) \times X_{Z}^{k}(t)\right)+\left(C_{Z}^{F}(t) \times \lambda_{z}(t)\right)\right) \leq \text { Budget }(t) \\
& \sum_{z=1}^{N Z} \sum_{t=1}^{T} \sum_{k=1}^{N D}\left(I N V_{z}^{k}(t) \times \gamma_{z}^{k}(t)\right) \times\left(1+D R^{-1}\right) \leq I N V \\
& \sum_{t=1}^{T} \sum_{k=1}^{N D}\left(\gamma_{z}^{k}(t)\right) \leq 1 \\
& \sum_{z=1}^{N Z} \sum_{k=1}^{M T i}\left(\left(\operatorname{Labor}_{z}^{t, M T} \times X_{z}^{k}(t)\right)+\left(\text { Labor }_{z}^{t, M T} \times \lambda_{z}(t)\right)\right) \leq \text { Labor }_{\text {Available }}^{\text {MT }}
\end{aligned}
$$




$$
\sum_{z=1}^{N Z} \sum_{k=1}^{N D}\left(\text { Labor }_{k}^{t t} \times X_{Z}^{t t}(t)\right) \leq \text { Labor }_{\text {Available }}^{t t}
$$

As demonstrated in (13) states that the total cost per year should not exceed the budget for that year. Equation (14) also emphasizes the limitation that the net present value of investment costs for all zones should be less than the amount of initial capital allocated to these zones. Also, in (15) notes that in long-term horizon (T), no more than one type of investment should be made for each zone. Equation (16) states that the number of man-hours for major and minor maintenance and emergency repairs per year should not exceed $L_{a b o r}^{M T}{ }_{\text {Available }}$, the number available per year. Likewise, in (17) the rate of man-hours for tree trimming per year should not exceed the number Labor tt tt

\section{STATISTICAL ANALYSIS OF OUTAGE DATA}

Statistical data in distribution networks provides operators, planners, and asset managers with valuable information on the performance and condition of the network and equipment. This data is collected in a variety of ways from a combination of software data such as computerized maintenance management system (CMMS), geographic information system (GIS), and communication networks such as supervisory control and data acquisition (SCADA) [22]. This information helps us to find equipment reliability indices, worst failure type, frequent failures, geolocation of failures and many more.

\section{CONDITION INDEX QUANTIFICATION}

Technically the best way to do this is to continuous monitoring of equipment condition. But in addition to high costs, this method requires a lot of infrastructure and effort [22]. In many cases the health index is defined to determine the condition of an equipment. The health index includes all the factors that are effective in determining equipment condition [21].

As illustrated in Table 1 the criteria are decoupled into four categories of vulnerability index, tree condition index, minor health index, and major health index. This decoupling has been made due to the static nature and dynamics of some indices over time, as well as to better reflecting the impact of each of the risk management actions on overhead line condition.

Table 1. Check list for inspection of one zone of overhead lines

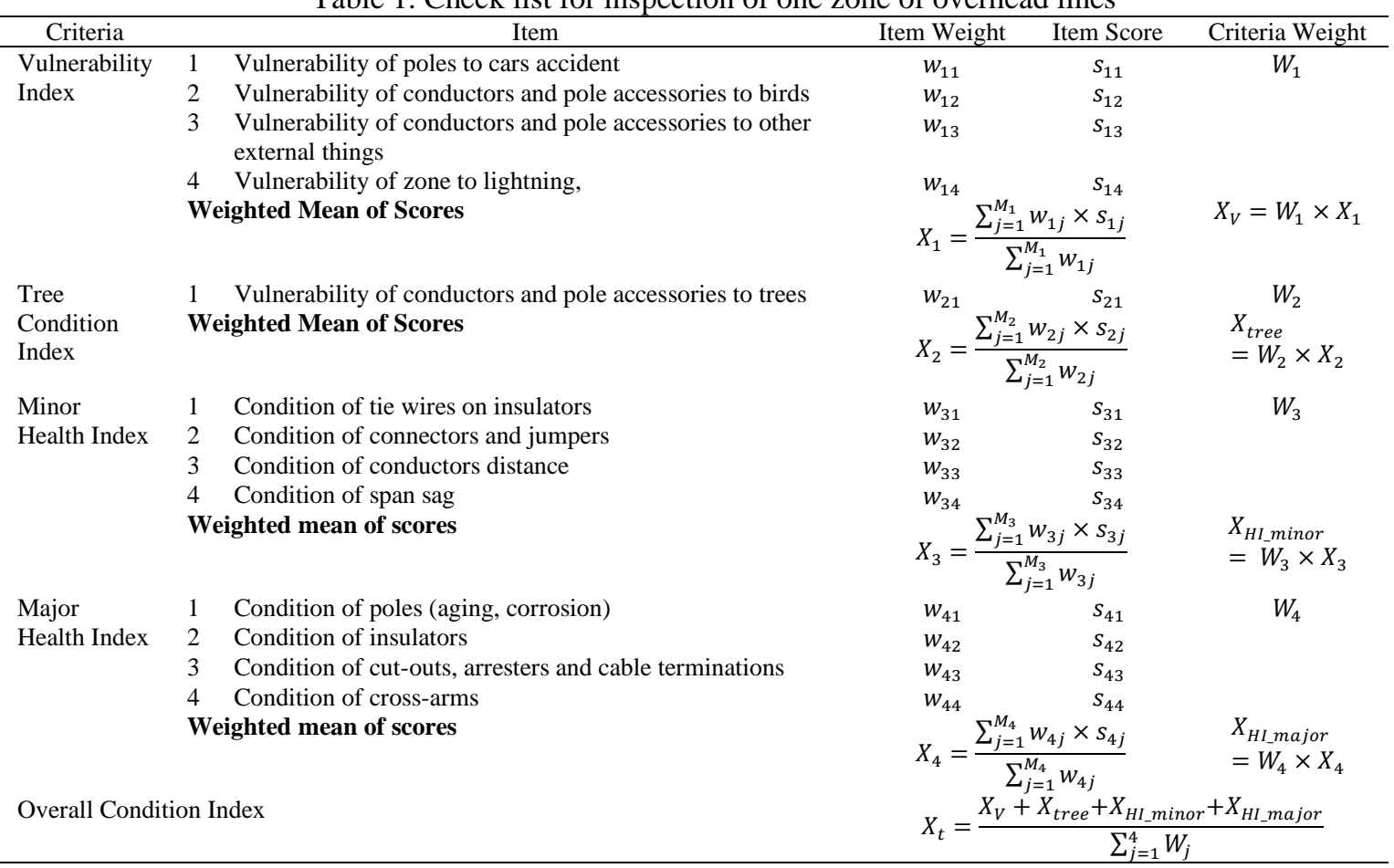


Another point in determining the factors affecting the overhead lines condition is the vulnerability of the overhead lines to external factors that are among the factors affecting the rate of outage or failure of the lines. The considering of this index was adopted after observing the extensive outages caused by these external factors in the statistical analysis. Table 1 was designed to determine the condition of a zone of feeders. The basis of zone division is the existence of maneuver points and the distance between two switching device. To quantification of the condition through this table, first each index is given a weight. A score will be assigned by the inspector for each index of each feeder zone. A score of 0 indicates the best and a score of 1 indicates the worst. The overall condition of each zone is calculated by the weighted average:

$$
X_{t}=\frac{X_{V}+X_{\text {tree }}(t)+X_{H I \_ \text {major }}(t)+X_{H I_{-} \text {minor }}(t)}{\sum_{j=1}^{4} W_{j}}
$$

in the (18), $X_{t}$ is the overall condition of each zone as a function of time, $X_{V}$ is the condition index of vulnerability factor, $X_{H_{-} \text {minor }}(t)$ is the minor health index and $X_{H_{-} \text {major }}(t)$ is the major health index of overhead line's component. This will be more explained in next subsection.

\subsection{Health index as function of time}

In many cases the health index is defined to determine the condition of an equipment. The health index includes all the factors that are effective in determining equipment condition. Equipment such as poles and cross arms, fittings and jumpers, tie conductors, cutouts, and switches are subject to deterioration and aging. The following equation determines the health index of overhead line as a function of time [23], [24].

$$
X_{H I}(t)=X_{H I}\left(e^{\beta_{H I}\left(t-t_{0}\right)}\right)
$$

In this equation, $X_{H I}(t)$ is an index of minor or major health at a particular time $t$ in the future. $X_{H I_{t 0}}$ is health index at time $t_{0}$ and $\beta_{H I}$ is a constant coefficient for scaling the equation.

\subsection{Trees condition index as function of time}

Trees are fast growing and can reach a critical point in about one to two years. If the tree branch approaches the bare lines, it is very likely that a failure will occur. In fact, the vulnerability of bare lines to trees is very high. Here, we want to estimate the vulnerability of lines to trees in each zone using a timebased model. If the condition index is between 0 (best) and 1 (worst) we assume that the condition will fall from 0.05 to 1 within 2 years. With this information, the unknown parameters of the (20) are obtained.

$$
X_{\text {tree }}(t)=X_{\text {tree }}\left(e^{\beta_{\text {tree }}\left(t-t_{0}\right)}\right)
$$

In the (20), $X_{\text {tree }}(t)$ is the condition index of the trees in each zone at time $X_{\text {tree }_{t 0}}$ is the current condition of the trees at time $t_{0}$ and $\beta_{\text {tree }}$ is the unknown variable of equation.

\subsection{Scoring method of items}

After determining the weight of each item, there is a need to set a framework for scoring the items. Since Table 1 is designed for the inspector, it should be as easy as possible for the inspector to assign a score to minimize errors and preferences in scoring. Therefore, for each item in Table 1, we will provide a selective framework for scoring. For example, the method of scoring an item is described next subsection.

\subsubsection{Span condition}

To determine the item's score, the inspector must specify the number of spans with a non-standard sag and length. There are an average of 200 poles in each zone. So, based on knowledge of utility expert, we give the worst score (number 1) to a zone that has more than 10 non-standard spans. The scoring framework for this index is given in Table 2 .

\subsection{Failure rate model}

The failure rate is a key parameter in risk analysis of distribution network and is known as an index and measure of reliability of the equipment and is also very closely related to the condition of the equipment. The worst condition of an equipment will result in the highest failure rate in the equipment [25]. In general, it can be said the best failure rate model is a model that, besides accurately estimating the failure rate, can cover all the factors involved in the outage of feeder, as well as reflecting the impact of maintenance, replacement, 
and all overhead lines preventive actions. In [25], a practical model is presented that, unlike common modeling which are as a function of time and age of the equipment, it models the failure rate of each equipment based on its equipment condition. The model presented is an exponential function of the failure rate as a function of condition. Equation (21) illustrates this function [25].

$$
\lambda(x)=\mathrm{A} e^{B x}+C \quad \text { failure } / \text { year }
$$

\begin{tabular}{ccc}
\multicolumn{3}{c}{ Table 2. Span inspection check list for each zone } \\
\hline Score (0 to 1) & Non-standard span (span/zone) & Item \\
\hline Span Condition & $x=1$ & 0.05 \\
$2 \leq x \leq 3$ & 0.2 \\
$3<x \leq 4$ & 0.4 \\
$4<x \leq 6$ & 0.7 \\
$6<x \leq 8$ & 0.8 \\
$8<x \leq 10$ & 0.9 \\
$x>10$ & 1 \\
\hline
\end{tabular}

\section{CASE STUDY}

The studied network consists of 10 feeders (19 zone) in Mashhad, that there are different types of feeders among them in terms of load type and geographical area. The set of customers who have an outage after each failure of the feeder and separation of the faulty part is defined as a zone. Therefore, a zone is considered between the two automation switch.

\subsection{Outage data analysis of case study}

Mashhad electricity distribution company (MCDC) with yearly distribution of $6661094 \mathrm{MWh}$, is one of the leading and important distribution companies in the electricity industry of Iran. However, there are various failures on the network each year due to different reasons. According to the information recorded in the information and outage management system of MCDC, about 4604 failures has occurred in the medium voltage feeders in Mashhad in the last five years, out of which 4190 were in the overhead lines. The all of these failures in the overhead medium voltage feeders Leading to $3816 \mathrm{MWh}$ energy not supplied.

\subsection{Parameter calculation of failure rate model}

To calculate the parameters A, B, and C of (21) for each zone, we will follow the description of [25]. First, we select the initial values from the [25] based on the length of each zone. But since the outage rate of each zone depends on the length of the feeder and various factors, it is therefore necessary to calibrate these values by using the Chi-square error method [25].

\subsection{Present condition calculation and condition model estimation}

To calculate the current condition of each equipment using Table 1, we obtain the weighted average of the characteristics and conditions of each zone in terms of its criteria and items. This average weight, which is the output of the table, indicates the condition of each zone under current conditions. The weight of the criteria and items is the same for its all feeders and related zones. To obtain minor and major $\beta_{H I}$ from the (19), (22) and (23) is deduced respectively. Given the 20 year life span for the overhead lines and their initial state of 0.05 , we obtain the $\beta_{H I}$. For $t_{0, \text { major }}$ and $t_{0, \text { minor }}$ it is reasonable to assume that they are equal to the year in which repairs are done.

$$
\begin{array}{r}
\beta_{H I \_ \text {minor }}=\frac{\ln \left(\frac{X_{H I_{t-\text { minor }}}}{X_{H I_{\text {t0-minor }}}}\right)}{t-t_{0, \text { minor }}} \\
\beta_{H I_{-} \text {minor }}=\frac{\ln \left(\frac{X_{H I_{t-\text { minor }}}}{X_{H I_{t 0-\text { minor }}}}\right)}{t-t_{0, \text { minor }}}
\end{array}
$$

Also to calculate $\beta_{\text {tree }}$ by using the (20), (24) is concluded. We assume the worst-case condition $X_{\text {tree }}=1$ for the bare conductor as 2 years, for the covered conductor as 4 years and for the ABC cables as 5 years and the initial condition value for all feeders is 0.05 . 


$$
\beta_{\text {tree }}=\frac{\ln \left(\frac{X_{\text {tree }}}{X_{\text {tree }_{0}}}\right)}{\left(t-t_{0}\right)}
$$

\subsection{Effect analysis of risk reduction actions}

By performing each of the actions described above and applying the improvement effects of that actions on the condition index of the overhead lines in Table 2, the effectiveness of each actions is measured. There are now 5 actions outlined above, each applied separately and the rate of improvement in each condition index after applying actions is reported in Table 3.

Table 3. Rate of reduction of decoupled condition indices after implementation of actions

\begin{tabular}{lcccc}
\hline \multicolumn{1}{c}{ Risk Reduction } & \multicolumn{2}{c}{ Rate of Reduction of Decoupled Condition Indices After Implementation of Actions (\%) } \\
Strategy & Minor Health Index & Major Health Index & Trees Condition Index & Vulnerability Index \\
\hline \#1 (Action 1+2) & 95 & 0 & 95 & 0 \\
\#2 (Action 3) & 0 & 95 & 0 & 0 \\
\#3 (Action 1+2+4) & 95 & 0 & 95 & 50 \\
\#4 (Action 3+5) & 95 & 95 & 95 & 70 \\
\#5 (Action 3+6) & 95 & 95 & 95 & 95 \\
\hline
\end{tabular}

Maintenance actions

- Action 1: trees trimming to prevent encountering branches with trees.

- Action 2: minor repairs including replacement of damaged joints, correction of conductor spacing, correction of length and flash of span and tie conductors.

- Action 3: general repairs including equipment repair, cross-arm replacement, defective insulators replacement or repairing damaged poles, and replacement aged equipment.

- Reinvestment actions

- Action 4: implementing covering of pole's accessories: this action directly improves the network's vulnerability to birds, external objects and trees.

- Action 5: replacing existing bare conductors with covered conductors: this action also has a direct impact on the amount of vulnerability to birds, external objects and trees. Of course, it is by itself vulnerable to storms and lightning. In the meantime and during implementation of the program, the connections, tie conductors, pole and cross-arms, the distance between the conductors and the bad span state will automatically corrected.

- Action 6: replacement of current bare conductors with $\mathrm{ABC}$ cable: $\mathrm{ABC}$ cable not only eliminates conditions such as poor span condition, conductor distance, tie conductors, jumper and cross-arm, it is durable against external factors, especially trees, storms and lightning is and does not have the disadvantages of a covered conductor.

Given that the overall condition of the feeder is resulted from the weighted average of the separated criteria, we therefore define that each action will only affect the self-relevant criteria. In accordance with Table 3, we define the strategies derived from the combination of the above actions. Rate of reduction of decoupled condition indices after implementation of actions are shown in Table 3 based on test and error using condition quantification framework in Table 1.

\subsection{Implementation of proposed algorithm on the case study}

In this section, the propsed model has been coded in the MATLAB [26] and solved by using priority-based genetic algorithm (priGA) 18] on the 10 feeders (19 zones) of the mashhad power distribution network described in the previous section, in 5-year horizons. The shortest path problem optimization model for 5-year horizon is shown in Figure 2. As it can be seen, we have 6 choices each year, depending on the specification of each zone and long-term scheduling, one of them will chose by the proposed algorithm. The chromosome dimensions of priGA after decoding for all zones will be $N Z \times T$, i.e. $19 * 5$ for the 5 -year horizon.

\subsection{Problem assumption}

Typically, in any research, there are assumptions to bring the situation closer to the real operating conditions. In the following, we will explain the assumptions we have made to solve this problem.

- Major maintenance will be carried out with the implementation of the $\mathrm{ABC}$ cable and coated conductor.

- As a result of implementation of $\mathrm{ABC}$ and covered conductor action, minor health index and tree condition index are also improved. In fact, we do not charge a separate cost to improve these indices. 
- Vulnerability to trees becomes less after running ABC cable and coated conductor. Therefore, the index of tree condition later returns to their bad condition.

- Along with the implementation of the investment action for covering of pole's accessories, the tree trimming action and the minor maintenance action is done too.

- If we use ABC cable, there is no need for any major repairs until the end of the period.

- We are only allowed to use one investment action for each zone in each period.

- $\quad$ Partial repairs are also done with the trimming.

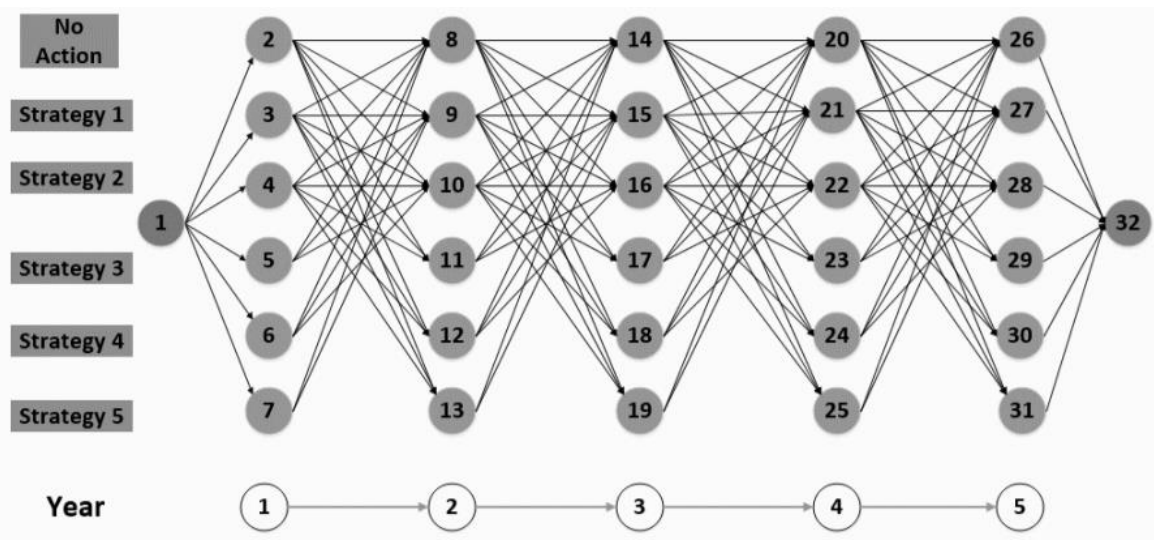

Figure 2. Shortest path problem for 5-year horizon

\subsection{Simulation result in 5 year horizon}

Simulation of the shortest path problem for finding the optimal strategy over the 5 years, is done based on model shown in Figure 2. In this problem, we have 6 options to choose each year. One option is to do no action on each zone, and the other 5 options include 5 different actions to improve the condition of each zone. By choosing an option for a year, for the following year only options can be selected that have a branch with the previous year option. In the following, we will examine the problems with considering constraints such as budget and labor.

There are always some constraints for solving optimization problems that ignoring them, will made the solutions of the problems unrealistic. In this case, there are constraints such as budget and labor, which are determined by their optimal values in unconstrained case. The values of these constraints are given in Table 4. After solving the problem by considering these constraints, the paths presented in Table 5 are obtained. priGA convergence curve and optimal scheduling of action implementation are shown in Figure 3 and Table 5 respectively.

In this case, for all zones, the implementation of the investment has been result. In addition, investment on covered conductors (action 5) is proposed for zone 4. Investment on ABC cable is not recommended for any zone because of the high capital cost. In the cost analysis, we find that the total cost in this case has increased by $9 \%$ due to the constraints. The results of Table 4 shows that the annual cost and labor costs for maintenance and tree trimming did not exceed the defined limits. As is clear from the results of the unconstrained solution, many of the results are more than the set constraints. In the unconstrained solution, we found that due to disregard of constraints, there was little maintenance during the fourth, seventh, and tenth years, but instead, labor and cost density is in other years that may exceed the capabilities and budget and labor capital which shows the importance of considering constraints.

Table 4. Result of optimization problem in 5-year horizon

\begin{tabular}{|c|c|c|c|c|c|c|}
\hline $\begin{array}{l}\text { Year } \\
\text { Yearly Result }\end{array}$ & $\overrightarrow{\text { Constraint }}$ & 1 & 2 & 3 & 4 & 5 \\
\hline Maintenance \& Failure Cost $(\mathrm{K} \$)$ & 800 & 754.7 & 688.55 & 700.1 & 600.9 & 602 \\
\hline Investment $(\mathrm{K} \$)$ & 800 & 649.4 & 165.3 & 8.4 & 0 & 0 \\
\hline Man-hour Labor for Maintenance & 9000 & 5572 & 8760 & 5074 & 3418 & 3983 \\
\hline Man-hour Labor for Tree Trimming & 300 & 227 & 91 & 222 & 188 & 209 \\
\hline Cost Function $(\mathrm{K} \$)$ & & \multicolumn{5}{|c|}{$3,257.8$} \\
\hline
\end{tabular}


Table 5. Risk Management action schedules of case study comprising 19 zones in 5-year horizon

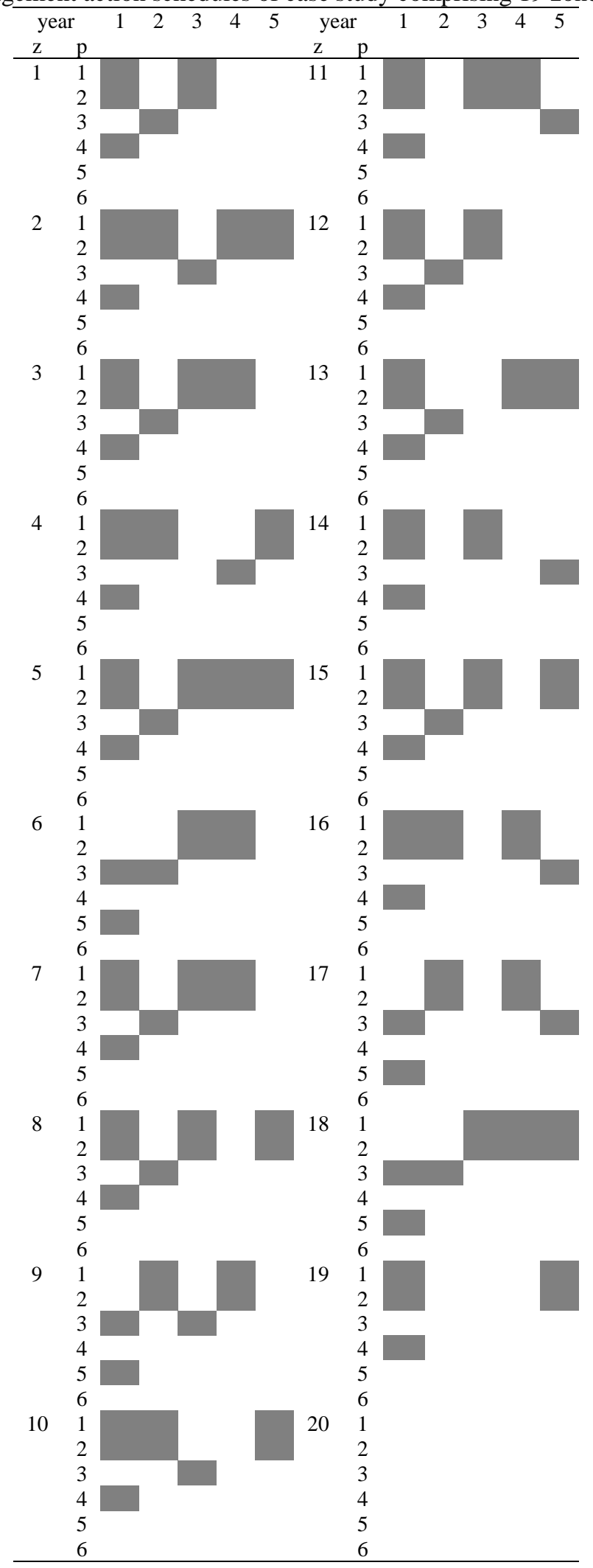




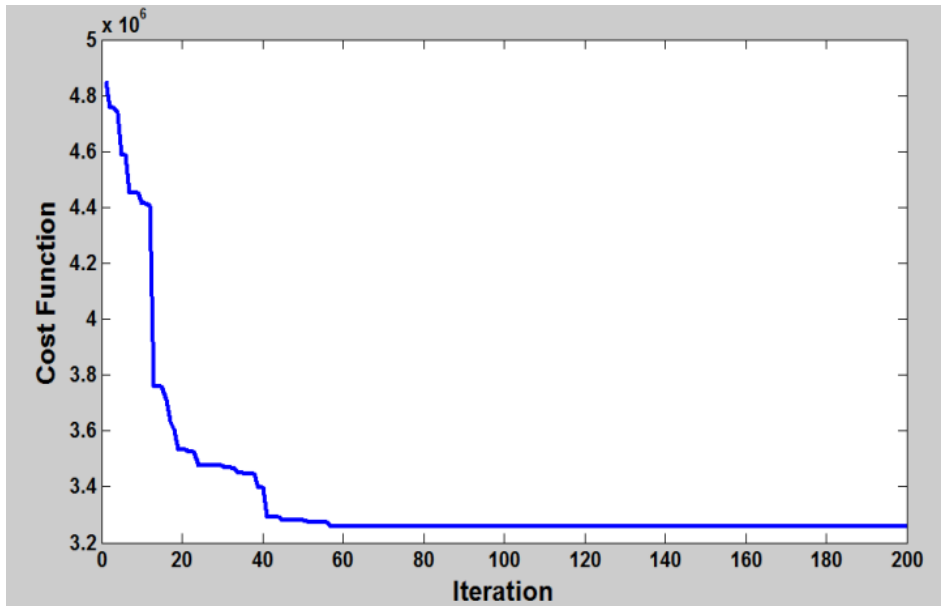

Figure 3. priGA convergence curve for 5-year horizon case

\section{CONCLUSION}

In this study, strategies have been proposed to improve risk, such as tree trimming, minor and major maintenance, covering pole accessories, replacement of bare conductors with covered conductors and ABCs. The shortest path problem model has been used to implement these strategies in the 5-year horizons. The results of applying the proposed method to the study network indicate that by considering of annual budget, available labor and allocated initial capital, zones with high loads, long repair times, and high failure rates require to replacement of bare conductor by covered conductor and other zones, they need to covering pole accessories. On average for all zones, minor maintenance and tree trimming are also done every other year, that confirming the validity of the modeling. The rate of major maintenance is also obtained on average every four years, which is consistent with the engineering logic of repairs. Overall, the results show the accuracy and precision of the proposed method.

\section{REFERENCES}

[1] R. Billinton and J. E. Billinton, "Distribution system reliability indices," IEEE Transactions on Power Delivery, vol. 4, no. 1, pp. 561-568, 1989, doi: 10.1109/61.19247.

[2] D. Zhang, W. Li, and X. Xiong, "Overhead line preventive maintenance strategy based on condition monitoring and system reliability assessment," IEEE Transactions on Power Systems, vol. 29, no. 4, pp. 1839-1846, 2014, doi: 10.1109/TPWRS.2013.2295379.

[3] L. Bertling, R. Allan, and R. Eriksson, "A reliability-centred asset maintenance method for assessing the impact of maintenance in power distribution systems," 2005 IEEE Power Engineering Society General Meeting, vol. 3, no. 1, p. 2649, 2005, doi: 10.1109/pes.2005.1489068.

[4] E. Abbasi, M. Fotuhi-Firuzabad, and A. Abiri-Jahromi, "Risk based maintenance optimization of overhead distribution networks utilizing priority based dynamic programming," 2009 IEEE Power and Energy Society General Meeting, PES ’09, pp. 1-11, 2009, doi: 10.1109/PES.2009.5275735.

[5] J. Korpijärvi, "Aging based maintenance and reinvestment scheduling of electric distribution network," Doctor of Science, Institute of Energy Technology, Acta Universitatis Lappeenrantaensis Lappeenranta, Finland, 2012.

[6] R. E. Brown and J. J. Burke, "Managing the risk of performance based rates," IEEE Transactions on Power Systems, vol. 15, no. 2, pp. 893-898, 2000, doi: 10.1109/59.867190.

[7] A. Abiri-Jahromi, M. Fotuhi-Firuzabad, and E. Abbasi, "An efficient mixed-integer linear formulation for long-term overhead lines maintenance scheduling in power distribution systems," IEEE Transactions on Power Delivery, vol. 24, no. 4, pp. 20432053, Oct. 2009, doi: 10.1109/TPWRD.2009.2028785.

[8] A. D. Janjic and D. S. Popovic, "Selective maintenance schedule of distribution networks based on risk management approach," IEEE Transactions on Power Systems, vol. 22, no. 2, pp. 597-604, 2007, doi: 10.1109/TPWRS.2007.894863.

[9] P. Dehghanian, M. Fotuhi-Firuzabad, F. Aminifar, and R. Billinton, "A comprehensive scheme for reliability-centered maintenance in power distribution systems - part ii: numerical analysis," IEEE Transactions on Power Delivery, vol. 28, no. 2, pp. 771-778, Apr. 2013, doi: 10.1109/TPWRD.2012.2227833.

[10] P. Dehghanian, M. Fotuhi-Firuzabad, F. Aminifar, and R. Billinton, "A comprehensive scheme for reliability centered maintenance in power distribution systems - part i: methodology," IEEE Transactions on Power Delivery, vol. 28, no. 2, pp. 761770, 2013, doi: 10.1109/TPWRD.2012.2227832.

[11] P. Wang and R. Billinton, "Reliability cost/worth assessment of distribution systems incorporating time-varying weather conditions and restoration resources," IEEE Transactions on Power Delivery, vol. 17, no. 1, pp. 260-265, 2002, doi: $10.1109 / 61.974216$

[12] M. Al-Muhaini and G. T. Heydt, "A novel method for evaluating future power distribution system reliability," IEEE Transactions on Power Systems, vol. 28, no. 3, pp. 3018-3027, 2013, doi: 10.1109/TPWRS.2012.2230195.

[13] M. Gui, A. Pahwa, and S. Das, "Bayesian network model with Monte Carlo simulations for analysis of animal-related outages in overhead distribution systems," IEEE Transactions on Power Systems, vol. 26, no. 3, pp. 1618-1624, 2011, doi: 
10.1109/TPWRS.2010.2101619.

[14] L. Goel, X. Liang, and Y. Ou, "Monte Carlo simulation-based customer service reliability assessment," Electric Power Systems Research, vol. 49, no. 3, pp. 185-194, Apr. 1999, doi: 10.1016/s0378-7796(98)00121-7.

[15] L. Goel, "Monte Carlo simulation-based reliability studies of a distribution test system," Electric Power Systems Research, vol. 54, no. 1, pp. 55-65, Apr. 2000, doi: 10.1016/S0378-7796(99)00066-8.

[16] C. F. Chang, "Reconfiguration and capacitor placement for loss reduction of distribution systems by ant colony search algorithm," IEEE Transactions on Power Systems, vol. 23, no. 4, pp. 1747-1755, 2008, doi: 10.1109/TPWRS.2008.2002169.

[17] K. Xie, J. Zhou, and R. Billinton, "Reliability evaluation algorithm for complex medium voltage electrical distribution networks based on the shortest path," IEE Proceedings: Generation, Transmission and Distribution, vol. 150, no. 6, pp. 686-690, 2003, doi: 10.1049/ip-gtd:20030797.

[18] M. Gen, R. Cheng, and L. Lin, "Network models and optmization multiobjective genetic algorithm approach," Network Models and Optmization Multiobjective Genetic Algorithm Approach, p. 522, 2008.

[19] C. J. Wallnerström, On incentives affecting risk and asset management of power distribution. 2011.

[20] K. Sand, O. Gjerde, and D. E. Nordgard, "Current risk exposure in the distribution sector. Initial study," SINTEF Energy Research, 2007.

[21] D. Hughes, G. Dennis, J. Walker, and C. Williamson, "Condition based risk management (CBRM) - Enabling asset condition information to be central to corporate decision making," Proceedings of the 1st World Congress on Engineering Asset Management, WCEAM 2006, pp. 1212-1217, 2006, doi: 10.1007/978-1-84628-814-2_133.

[22] J. Schneider et al., "Asset management techniques," International Journal of Electrical Power and Energy Systems, vol. 28, no. 9, pp. 643-654, 2006, doi: 10.1016/j.ijepes.2006.03.007.

[23] R. S. Blake, "Methodologies for the evaluation and mitigation of distribution network risk," Durham University, 2010.

[24] B. Wareing, "Wood pole overhead lines," Wood Pole Overhead Lines, pp. 1-337, 2005, doi: 10.1049/PBPO048E.

[25] R. E. Brown, G. Frimpong, and H. L. Willis, "Failure rate modeling using equipment inspection data," IEEE Transactions on Power Systems, vol. 19, no. 2, pp. 782-787, 2004, doi: 10.1109/TPWRS.2004.825824.

[26] B. R. Hunt, R. L. Lipsman, and J. M. Rosenberg, A Guide to MATLAB®, vol. 39, no. 06. Cambridge University Press, 2014.

\section{BIOGRAPHIES OF AUTHORS}
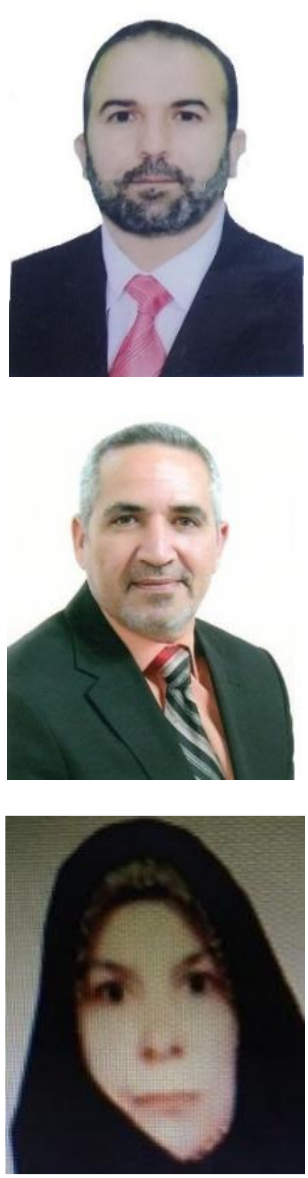

Adnan Hasan Tawafan (iD) 8 SC P was born in Kerbala, Iraq, in 1971. He received the M.S. degree in electrical engineering from University of Technology, Baghdad, Iraq in 2002, and the Ph.D. degree in electrical engineering from UTeM, Malaysia in 2014. Since 2005, he has been with electrical technical department in Technical Institute of Karbala, Iraq. His research interests concern: analysis and design of distribution system, protection, power quality improvement, power electronics applications and risk management. He can be contacted at email: inkr.adn@atu.edu.iq.

Dhafer Mayoof Alshadood (D) If SC P was born in Nasiriyah, Iraq, in 1963. He received the B.S. degree in electrical engineering from Basra University, Basra, Iraq in 1987, and the M.S. degree in electrical engineering from Ferdowsi University, Iran in 2018. Currently, he is PHD student in Shahid Chamran University, Iran. He has been with electrical technical department in Nasiriyah Technical Institute, Iraq scine 2010 until 2019. His research interests concern: analysis and design of distribution system, power electronics applications, protection, power quality improvement and risk management. He can be contacted at email: eng.dafer@stu.edu.iq.

Fatima Kadhem Abd (iD) 8d SC P was born in Kerbala, Iraq, in 1968. She received the B. degree in electrical engineering from University of technology, Baghdad, Iraq in 1990, Since 2000, she has been with electrical technical department in Technical Institute of Karbala, Iraq. Her research interests concern: analysis of distribution system. She can be contacted at email: fatima@kit.edu.iq. 